\title{
PENGARUH TEKANAN KERJA TERHADAP TINGKAT KINERJA KARYAWAN PADA BANK MEGA SYARIAH KC PALU
}

\author{
Irham Pakkawaru¹, Abdul Jalil2, Arman³, Rizqa Sabrina ${ }^{4}$ \\ ${ }^{1}$ Jurusan Perbankan, Fakultas Ekonomi dan Bisnis Islam, IAIN Palu, \\ ${ }_{2}^{2}$ Jurusan Perbankan, Fakultas Ekonomi dan Bisnis Islam, IAIN Palu, abdul_jaliil@iainpalu.ac.id \\ ${ }^{3}$ Jurusan Perbankan, Fakultas Ekonomi dan Bisnis Islam, IAIN Palu, maskaarman89@gmail.com \\ ${ }_{4}^{4}$ Jurusan Perbankan, Fakultas Ekonomi dan Bisnis Islam, IAIN Palu,
}

\section{ABSTRAK}

Tekanan kerja adalah suatu kondisi ketegangan yang menciptakan adanya ketidakseimbangan fisik dan psikis, mempegaruhi emosi, proses berpikir, dan kondisi seorang karyawan tujuan yang ingin dicapai dalam penelitian ini adalah Untuk mengetahui tekanan kerja dapat merubah kinerja karyawan pada Bank MEGA Syariah KC Palu, Untuk mengetahui pengaruh tekanan kerja terhadap kinerja karyawan pada Bank MEGA Syariah KC Palu. Rumusan masalah dalam penelitian ini adalah Apakah tekanan kerja berpengaruh terhadap kinerja karyawan pada Bank MEGA Syariah KC Palu. Populasi dalam penelitian ini adalah seluruh karyawan Bank Mega KC Palu yang berjumlah 25 orang. Teknik pengambilan sampel yang digunakan adalah teknik sampel jenuh (saturation sampling), dengan menggunakan rumus sampel jenuh menurut Sugiyono. Teknik pengumpulan data adalah melalui teknik observasi dan kuesioner. Kemudian teknik analisa yang digunakan adalah analisi regresi linear sederhana. Hasil olahan statistik yang dibantu dengan program SPSS 16.0 for windows, memiliki nilai t-hitung sebesar 7,129> nilai $t$-tabel sebesar 1,988, serta tingkat signifikannya yaitu $0,74<0,05$, menunjukan bahwa Tekanan Kerja memiliki hubungan positif namun tidak berpengaruh secara signifikan terhadap kinerja karyawan pada Bank Mega KC Palu. Dari kesimpulan yang diperoleh disarankan agar seorang pemimpin terus memberikan dukungan dan perasaan yang aman pada karyawan, agar sumber daya yang ada terus meningkat demi terwujudnya tujuan organisasi.
INFORMASI

ARTIKEL

\section{Katakunci:}

Tekanan Kerja, Kinerja Karyawan 


\section{PENDAHULUAN}

Salah satu faktor yang mempengaruhi tingkat keberhasilan suatu organisasi adalah kinerja karyawan. Kinerja karyawan adalah hasil kerja secara kualitas dan kuantitas yang dicapai oleh seorang karyawan dalam melaksanakan tugasnya sesuai dengan tanggung jawab yang diberikan kepadanya. Setiap perusahaan selalu mengharapkan karyawannya mempunyai prestasi, karena dengan memiliki karyawan yang berprestasi akan memberikan sumbangan yang optimal bagi perusahaan. Selain itu, dengan memiliki karyawan yang berprestasi perusahaan dapat meningkatkan kinerja perusahaannya. Apabila individu dalam perusahaan yaitu sumber daya manusia berjalan efektif, maka perusahaan juga tetap berjalan efektif. Dengan kata lain kelangsungan suatu perusahaan ditentukan oleh kinerja karyawannya. ${ }^{1}$

Masalah yang mempengaruhi kinerja karyawan sangatlah banyak dan ini sebagai tantangan tersendiri untuk perusahaan dalam mengelolah sumber daya manusia karena keberhasilan suatu perusahaan itu tergantung pada sumber daya manusia yang berkualitas. Istilah kinerja berasal dari kata job performance atau actual performance (prestasi kerja atau prestasi sesumgguhnya yang dicapai seseorang) yaitu hasil kerja (output) secara kualitas dan kuantitas yang dicapai oleh seorang karyawan dalam melaksanakan tugasnya sesuai dengan tanggung jawab yang diberikan kepadanya output perusahaan yang

1 Anggit Astianto, Dkk. dalam skripsi Fina Nailatul Izzah "Pengaruh pengawasan dan beban kerja terahadap kinerja karyawan di konveksi "Lida Jaya" padurenan gebok kudus, http://eprints.stainkudus.ac.id/id/eprint/157 diakses 20 januari 2019 buruk dapat disebabkan oleh penurunan kinerja karyawan, dan hal ini dapat terlihat ketika karyawan tidak dapat menyelesaikan pekerjaan dengan target kualitas dan kuantitas yang ditentukan oleh perusahaan. ${ }^{2}$

Kinerja karyawan yang terjadi pada Bank Mega Syariah sudah cukup baik. Dilihat dari beberapa karyawan yang lembur untuk menyelesaikan pekerjaan yang belum selesai dan patuh dengan aturan yang ditetapkan perusahaan, Walaupun masih ada beberapa karyawan yang datang tidak tepat waktu.

Ketika karyawan menghadapi tekanan yang tinggi maka energi yang ada pada karyawan akan tercurah untuk menghadapi tekanan tesebut, sehingga energi karyawan untuk bekerja semakin berkurang dan kinerja yang dilakukan karyawan menjadi lebih jelek. Apabila kinerja karyawan jelek, maka hasil pekerjaan akan menjdi tiadak maksimal, bahkan terkesan asal-asalan. ${ }^{3}$

Hal ini menunjukan bahwa stress kerja merupakan salah satu factor yang mempengaruhi kinerja karyawan, karena stress berkaitan dengan tanggapan penyesuaian individu atas tekanan di tempat kerja. Karyawan sering dihadapkan dengan berbagai masalah dalam tempat kerja. Stres pekerjaan dapat diartikan sebagi tekanan yang dirasakan karyawan karena tugas-tugas pekerjaan tidak dapat mereka penuhi. Artinya, stres

2 Mangkunegara (2000.67) dalam skripsi dani praditya setiawan "Pengaruh beban kerja dan lingkungan kerja terhadap kinerja karyawan PT Macana Jaya cemerlang jawa tengah" (Yogjakarta : Universitas Negeri Yogjakarta, 2016)

${ }^{3}$ Ibid.02 
muncul saat karyawan tidak mampu memenuhi apa yang menjadi tuntutan-tuntutan pekerjaan. ${ }^{4}$

Tekanan kerja dapat didefinisikan sebagai kesadaran atau perasaan disfungsi pribadi sebagai akibat kondisi atau kejaian yang dirasakan di tempat kerja, dan juga reaksi psikologis dan fisiologis karyawan yang disebabkan oleh situasi yang dirasa tidak nyaman ini, tidak diinginkan, atau ancaman langsung di lingkungan tempat kerja karyawan. ${ }^{5}$

Tekanan kerja akan menciptakan ketegangan fikiran,emosional dan pada akhirnya akan tercermin dalam perilaku mereka. Ketegangan yang timbul dari tekanan kerja ini akan menciptakan ketidaknyamanan kerja seseorang dan akan menurunkan kinerja seseorang, berdasarkan hal tersebut, penulis puntertarik untuk mengatahui dan mengenali lebih dalam mengenai pengaruh tekanan kerja terhadap kinerja karyawan pada Bank Mega Syariah KC Palu

\section{TINJAUAN PUSTAKA}

\subsection{Tekanan Kerja}

Tekanan kerja atau job stress adalah perasaan tertekan yang dialami karyawan dalam menghadapi pekerjaan. Antara lain emosi tidak stabil, perasaan tidak tenang, suka menyendiri, sulit tidur, merokok yang berlebihan, tidak

4 Abdul Jalil. Pengaruh Stres Kerja terhadap Kinerja Pegawai pada Madrasah Aliyah Negeri 2 Model Palu. Scolae: Journal of Pedagogy, 3(1), 40-48. (2020)

5 Motgomer et al, dalam skripsi Rizki aulia kusuma wisanto" Analisis dampak locus of control pada tekanan kerja, kepuasan kerja dan kinerja auditor" (Diponegoro : Universitas diponegoro), 2012.,15 http://eprints.undip.ac.id diakses 19 april 2019 bisa rileks, cemas, tegang, gugup, dan tekanan darah yang meningkat. ${ }^{6}$

Tekanan kerja adalah suatu kondisi ketegangan yang menciptakan adanya ketidakseimbangan fisik dan psikis, mempegaruhi emosi, proses berpikir, dan kondisi seorang karyawan.7 Tekanan yang terlalu besar dapat mengancam kemampuan seseorang untuk menghadapi lingkungan. Sebagai hasilnya, pada diri para karyawan berkembang berbagai macam gejalah, dan dapat mengganggu pelaksanan kerja mereka. ${ }^{8}$ Orang-orang yang mengalami tekanan bisa menjadi nervous dan kekhawatiran kronis.

Telah dijelaskan didalam Alquran, QS Al-Insyirah: 94: 5-8 bahwa setelah kesulitan pasti ada kemudahan. Seperti halnya tekanan kerja yang berat akan menjadi mudah jika sudah sering dikerjakan

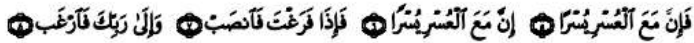

Terjemahnya:

"Karena Sesungguhnya sesudah kesulitan itu ada kemudahan, Sesungguhnya sesudah kesulitan itu ada kemudahan. Maka apabila kamu telah selesai (dari

6 A.A Anwar prabu mangkunegara, "Manajemen Sumber Daya Manusia Perusahaan" ( Bandung : PT Remaja Rosdakarya offset-) 2011.,157

7 Nurdin, N., Stockdale, R., \& Scheepers, H. (2012). The Influence of External Institutional Pressures on Local E-Government Adoption and Implementation: A Coercive Perspective within an Indonesian Local EGovernment Context. In H. Scholl, M. Janssen, M. Wimmer, C. Moe \& L. Flak (Eds.), EGovernment and E-Participation (Vol. 7443, pp. 1326): Springer Berlin / Heidelberg.

8 Nurdin, N. (2018). Institutional Arrangements in E-Government Implementation and Use: A Case Study From Indonesian Local Government. International Journal of Electronic Government Research (IJEGR), 14(2), 44-63. doi: 10.4018/ijegr.2018040104 
sesuatu urusan), kerjakanlah dengan sungguhsungguh (urusan) yang lain dan hanya kepada Tuhanmu lah hendaknya kamu berharap"9

\subsection{Faktor yang mempengaruhi tekanan kerja}

Penyebab tekanan kerja, antara lain beban kerja yang dirasakan terlalu berat, waktu kerja yang mendesak, kualitas pengawasan kerja yang rendah, iklim kerja yang tidak sehat, otoritas kerja yang tidak memadai yang berhubungan dengan tanggung jawab, konflik kerja, perbedaan nilai antara karyawan dengan pimpinan yang frustasi dalam kerja. ${ }^{10}$

Mendeteksi penyebab tekanan dan bentuk reaksinya, maka ada 3 pola dalam mengatasi tekanan, yaitu pola sehat, pola harmonis, dan pola psikologis.

Untuk menghadapi tekanan dengan cara sehat atau romantis, tentu banyak hal yang dapat dikaji. Dalam menghadapi tekanan, dapat dilakukan dengan tiga

strategi, yaitu:

1. Memperkecil dan mengendalikan sumber-sumber tekanan.

2. Menetralkan dampak yang ditimbulkan oleh tekanan.

3. Meningkatkan daya tahan pribadi. ${ }^{11}$

\subsection{Pengertian Kinerja}

Istilah kinerja berasal dari kata job performance atau Actual performance (prestasi kerja atau prestasi

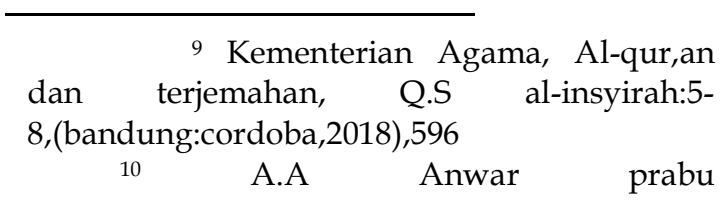

Perusahaan"(Bandung: PT Remaja Rosdakarya offset-), 2011.,157

11 Ibid. 159 sesengguhnya yang dicapai oleh seorang). Pengertian kinerja (prestasi kerja) adalah hasil kerja secara kualitas dan kuantitas yang dicapai oleh seorang pegawai dalam melaksanakan tugas sesuai dengan tanggung jawab yang diberikan padanya. ${ }^{12}$

Kinerja dapat dipandang sebagai proses maupun hasil pekerjaan. Kinerja merupakan suatu proses tentang bagai mana pekerjaan berlangsung untuk mencapai hasil kerja. Namun, hasil pekerjaan itu sendiri juga menunjuka kinerja. Terdapat beberapa faktor yang perlu diperhatikan untuk suatu organisasi mempunyai kinerja yang baik, yaitu menyangkut pernyataan tentang maksut dan nilai-nilai, manajemen strategis, manajemen sumber daya manusia, pengembangan organisasi, konteks organisasi, desain kerja, fungsionalisasi, budaya, dan kerja sama. ${ }^{13}$

Di dalam Al-Qur'an, Allah telah memerintahkan kepada makhluknya untuk senantiasa bekerja dengan kinerja yang tinggi. Terdapat di dalam QS AtTaubah: 9 ayat 105:

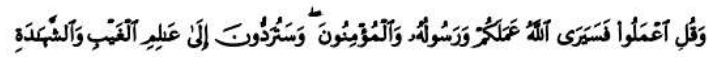

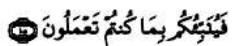

Terjemahnya:

"dan Katakanlah: "Bekerjalah kamu, Maka Allah dan Rasul-Nya serta orang-orang mukmin akan melihat pekerjaanmu itu, dan kamu akan dikembalikan kepada (Allah) yang mengetahui akan yang ghaib dan yang

12 8A.A Anwar prabu mangkunegara,
"Manajemen Sumber Daya
Perusahaan" (Bandung: PT Remaja Rosdakarya
offset-), 2011.,67 13 Wibowo,"manajemen kinerja" (Jakarta: Pt Rajagrafindo persada),.81

e-ISSN: 2686-6625 
nyata, lalu diberitakan-Nya kepada kamu apa yang telah kamu kerjakan."14

\subsection{Faktor yang mempengaruhi kinerja}

Pencapainyan kinerja adalah faktor kemampuan (ability) dan faktor motivasi (motivation). Hal ini sesuai dengan pendapat keith davis, (1964:484) yang merumuskan bahwa:

1. Human perfomance $=$ Ability + Motivation

2. Motivation $=$ Attitude+situation

3. Ability = Knowledge+skill

Dengan demikian kinerja merupakan suatu fungsi dari motivasi dan kemampuan. Untuk menyelesaikan tugas atau pekerjaan seseorang sepatutnya memiliki derajat kesediaan dan tingkat kemampuan tertentu. Kesediaan dan keterampilan seseorang tidaklah cukup efektif untuk mengerjakan sesuatu tampa pemahaman yang jelas tentang apa yang akan dikerjakan dan bagai mana mengerjakanya. Kinerja merupakan perilaku yang nyata yang ditampilkan setiap orang bagai mana prestasi kerja yang dihasilkan karyawan sesuai prennya dalam perusahaan. Kinerja karyawan merupakan suatu hal yang sangat penting dalam upaya perusahaan untuk mencapai tujuannya. ${ }^{15}$

\subsection{Penilaian Kinerja}

Penilaian kinerja mengacu pada suatu sistem formal dan terstruktur yang digunakan untuk mengukur, menilai dan memengaruhi sifat-sifat yang berkaitan dengan pekerjaan, perilaku dan hasil, termaksut tingkat ketidakhadiran. Dengan demikian,

${ }^{14}$ Kementerian Agama, Al-qur,an dan terjemahan, Q.S attaubah:105,(bandung:cordoba,2018),450

15 Thoby Mutis, Dkk. "Manajemen sumber daya manusia untuk perusahaan"(Jakarta:, Raja Grafindo persada), 2009.,406 penilaian prestasi adalah merupakan hasil kerja karyawan dalam lingkup tanggung jawabnya.

Apabila penilaian karyawan dilakukan dengan benar, para karyawan, para penyelia, departemen SDM dan akhirnya perusahaan akan diuntungkan dengan adanya kepastian bahwa upaya-upaya individu memberikan kontribusi kepada fokus strategi perusahaan. Pada prinsipnya penilaian kinerja adalah merupakan cara pengukuran kontribusi-kontribusi dari individu dalam instansi yang dilakukan terhadap organisasi. Nilai penting dari penilaian kinerja adalah menyangkut penentuan tingkat kontribusi individu atau kinerja yang diekspresikan dalam penyelesaian tugas-tugas yang menjadi tanggung jawabnya.

\subsection{Langkah-langkah dalam penilaian kinerja}

Proses penilaian kinerja terbagi dalam beberapa tahapan kegiatan sebagai berikut :

1. Identifikasi tujuan yang ingin dicapai oleh organisasi dengan adanya sistem penilaian kinerja yang akan disusun. Hal ini menjadi penting karena dengan mengetahui tujuan yang ingin dicapai akan lebih memudahkan dalam menentukan desain penilaian kinerja.

2. Menetapkan standar yang diharapkan dari suatu jabatan, sehingga akan diketahui dimensi-dimensi apa saja yang akan diukur dalam penilaian kinerja.

3. Menentukan desain yang sesuai untuk mencapai tujuan yang diharapkan. Penentuan desain penilaian kinerja ini harus selalu dikaitkan dengan tujuan penilaian. 
Hal ini karena tiap-tiap desain penilaian kinerja memiliki kelemahan dan kelebihannya masingmasing.

4. Melakukan penilaian kinerja terhadap pegawai yang menduduki suatu jabatan. Penilaian kierja ini dapat dilakukan oleh atasan saja, atau dengan sistem 360. Penilaian dengan sistem 360 maksudnya adalah penilaian satu pegawai dilakukan oleh atasan, rekan kerja yang sejajar/setingkat, dan bawahannya.

5. Evaluasi terhadap sistem penilaian kinerja yang telah dilakukan juga dilaksanakan pada tahap ini. Apakah penilaian kinerja tersebut sudah dapat mencapai tujuan dari diadakannya penilaian kinerja atau belum. ${ }^{16}$

\section{METHODOLOGY}

Jenis penelitian ini adalah verivikatif yaitu metode yang bertujuan untuk menguji secara matematis dugaan mengenai adanya hubungan variabel dari masalah yang sedang diselidiki di dalam hipotesis. ${ }^{17,18}$

Pendekatan yang dilakukan dalam penelitian ini adalah pendekatan kuantitatif, 19 menggunakan pendekatan

16 Wahibur Rokhman, "Manajemen Sumber Enterprise), 2011,. 72-73

17 Rully indrawan dan poppy

Yuniawati, metode penelitian, (Cet. I, Bandung :

PT. Rafika Aditama, 2004) 117

18 Nurdin, N., Azizah, W. N., \& Rusli, R. (2020). Pengaruh Pengetahuan,Kemudahan dan Risiko Terhadap Minat Bertransaksi Menggunakan Finansial Technology (Fintech) Pada Mahasiswa Institut Agama Islam Negeri (IAIN) Palu Jurnal Ilmu Perbankan dan Keuangan Syariah, 2(2), 199-222.

19 Nurdin, N., Musyawarah, I., Nurfitriani, N., \& Jalil, A. (2020). Pengaruh Pelayanan Mobile Banking Terhadap Kepuasan Nasabah (Studi Pada Mahasiswa Perbankan kuantitatif karena data penelitian tersebut berupa angka-angka dapat ditafsirkan atau dianalisis menggunakan statistik. ${ }^{20}$

Adapun lokasi penelitian adalah pada PT Bank MEGA Syariah Kota Palu Provinsi Sulawesi Tengah yang beralamat dijalan Jenderal Sudirman, Besusu Barat, Kecamatan Palu Timur, Kota Palu, Sulawesi tengah.

Populasi dalam penelitian adalah Karyawan Bank MEGA Syariah yang berjumlah 25 Karyawan. ${ }^{21}$ Kemudian untuk menentukan besarnya sampel, Sampel dalam peneitian ini adalah seluruh karyawan Bank MEGA Syariah KC Palu dengan menggunakan tehnik pengambilan sampel jenuh (saturation sampling), yaitu teknik pengambilan sampel bila semua anggota populasi digunakan sebagai sampel, dengan syarat populasi tidak terlalu banyak.

Teknik analisis data yang digunakan dalam penelitian ini adalah analisis kuantitatif. Yaitu proses analisis yang terdapat data-data yang berbentuk angka dengan cara perhitungan secara statistik untuk mengukur pengaruh Tekanan kerja terhadap tingkat kinerja karyawan pada Bank MEGA Syariah KC Palu. Analisa data dilakukan melalui tahap uji validitas, reabilitas, uji regresi beroanda, dan uji asumsi klasik. Untuk pembuktian hipotesis penulis menggunakan uji f dan uji t. ${ }^{22}$

Syariah IAIN Palu) Jurnal Ilmu Perbankan dan Keuangan Syariah, 2(2), 87-104.

20 Sofian Siregar, Statistik Parametrik untuk Penelitian Kuantitatif, Edisi 1, Cet. 3, (Jakarta: PT. Bumi Aksara, 2015), 30.

${ }^{21}$ Dicky Prayuda, wawancara dengan

penulis, Bank Mega Syariah Kota Palu, Palu, 8 Juni

22 Abdul Jalil . Pengaruh Beban Kerja, Stres Kerja dan Lingkungan Kerja Terhadap Kinerja Guru Madrasah Aliyah Negeri 2 Kota 


\section{HASIL DAN PEMBAHASAN}

\subsection{Deskripsi Umum Subjek Penelitian}

Penelitian menggunakan

instrumen kuesioner yang dibagikan

Karyawan Bank Mega Syariah yang sebagai sampel penelitian. Penyebaran kuesioner disebarkan oleh peneliti kepada sampel yang diteliti dengan perincian seperti dalam tabel berikut ini:

Tabel 1

Deskripsi Kuesioner

\begin{tabular}{|c|c|c|c|c|}
\hline $\begin{array}{c}\text { Jumlah } \\
\text { Sampel }\end{array}$ & $\begin{array}{c}\text { Kuesioner } \\
\text { Disebar }\end{array}$ & $\begin{array}{c}\text { Kuesioner } \\
\text { Kembali }\end{array}$ & $\begin{array}{c}\text { Kuesioner } \\
\text { Diolah }\end{array}$ & Presentase \\
\hline 25 & 25 & 25 & 25 & $100 \%$ \\
\hline
\end{tabular}

Sumber : Data Primer, 2020

Pada tabel diatas dijelaskan bahwa jumlah sampel yang digunakan adalah sebanyak 25 Karyawan.

Tabel 2

Deskripsi Responden

\begin{tabular}{|c|c|c|}
\hline $\begin{array}{c}\text { Jenis } \\
\text { Kelamin }\end{array}$ & Responden & Persentase \\
\hline Laki-laki & 14 & $56 \%$ \\
\hline Perempuan & 11 & $44 \%$ \\
\hline Jumlah & 25 & $100 \%$ \\
\hline
\end{tabular}

Sumber : Data Primer, 2020

Pada tabel diatas menunjukkan bahwa responden atau sampel yang berjumlah 25 orang dalam penelitian ini terbagi atas yang berjenis kelamin lakilaki berjumlah 14 orang (56\%) sedangkan yang berjenis kelamin perempuan berjumlah 11 orang (44\%), sehingga terlihat bahwa sampel

Palu. Jurnal Ilmu Perbankan dan Keuangan Syariah, 1(2), 117-134. 2019 penelitian didominasi oleh responden yang berjenis kelamin laki-laki.

\subsection{Uji Validitas dan Reliabilitas}

\subsubsection{Uji Validitas}

Uji validitas yaitu mengkorelasikan masing-masing pernyataan dengan jumlah skor untuk masing-masing variabel. Syarat minimum untuk memenuhi syarat adalah apabila $r=0,3$ jadi apabila korelasi antar butir dengan skor total kurang dari 0,3 maka instrumen tersebut tidak valid. ${ }^{23}$

Tabel 3 Uji Validitas

\begin{tabular}{|c|c|c|c|c|}
\hline Variabel & $\begin{array}{c}\text { Item } \\
\text { Pernyataan }\end{array}$ & $\begin{array}{l}\text { Corrected } \\
\text { Item total } \\
\text { Correlation }\end{array}$ & $\begin{array}{c}\mathrm{R} \\
\text { Kritis }\end{array}$ & Ket. \\
\hline \multirow{13}{*}{$\begin{array}{l}\text { Tekanan } \\
\text { Kerja }\left(X_{1}\right)\end{array}$} & 1 & 0,390 & 0,30 & Valid \\
\hline & 2 & 0,349 & 0,30 & Valid \\
\hline & 3 & 0,302 & 0,30 & Valid \\
\hline & 4 & 0,361 & 0,30 & Valid \\
\hline & 5 & 0,421 & 0,30 & Valid \\
\hline & 6 & 0,347 & 0,30 & Valid \\
\hline & 7 & 0,393 & 0,30 & Valid \\
\hline & 8 & 0,337 & 0,30 & Valid \\
\hline & 9 & 0,310 & 0,30 & Valid \\
\hline & 10 & 0,545 & 0,30 & Valid \\
\hline & 11 & 0,491 & 0,30 & Valid \\
\hline & 12 & 0,754 & 0,30 & Valid \\
\hline & 13 & 0,468 & 0,30 & Valid \\
\hline \multirow{11}{*}{$\begin{array}{c}\text { Kinerja } \\
\text { Karyawan } \\
(\mathrm{Y})\end{array}$} & 1 & 0,378 & 0,30 & Valid \\
\hline & 2 & 0,322 & 0,30 & Valid \\
\hline & 3 & 0,328 & 0,30 & Valid \\
\hline & 4 & 0,512 & 0,30 & Valid \\
\hline & 5 & 0,538 & 0,30 & Valid \\
\hline & 6 & 0,305 & 0,30 & Valid \\
\hline & 7 & 0,413 & 0,30 & Valid \\
\hline & 8 & 0,563 & 0,30 & Valid \\
\hline & 9 & 0,441 & 0,30 & Valid \\
\hline & 10 & 0,516 & 0,30 & Valid \\
\hline & 11 & 0,584 & 0,30 & Valid \\
\hline
\end{tabular}

Berdasarkan tabel di atas diatas hasil uji validitas, maka dapat dinyatakan bahwa semua instrumen layak ikut sertakan dalam penelitian ini, karena koefisien korelasi (r-hitung)

23 Sugiyono, Metode Penelitian Kuantitatif, Kualitatif dan $R$ an $D$, (Cet.XIII, Bandung: CV. Alfabeta, 2011), 20. 
seluruh item pernyataan yang diperoleh lebih besar dari nilai rkritis yaitu 0,30.

\subsubsection{Uji Reliabilitas}

Pengujian reliabilitas dilakukan dengan internal consistensy atau derajat ketepatan jawaban. Untuk penelitian ini digunakan Statistical Packaged For social Sciences (SPSS) sebagai alternatif pengujian reliabilitas untuk mengetahui konsistensi hasil sebuah jawaban tentang tanggapan responden. Untuk melakukan pengujian reliabititas penulis menggunakan SPSS versi 16.0, yaitu dalam mengukur reliabilitas disini menggunakan uji statistik Cronbach Alpha (a), yang mana satu variabel dikatakan reliabel jika memiliki Cronbach Alpha lebih dari $0,60(>0,60) .{ }^{24}$

Tabel 4 Uji Reliabilitas

\begin{tabular}{|c|c|c|c|}
\hline Variabel & $\begin{array}{c}\text { Reliability } \\
\text { Coeficients }\end{array}$ & $\begin{array}{c}\text { Cronbach } \\
\text { Alpha }\end{array}$ & Keterangan \\
\hline $\begin{array}{c}\text { Tekanan Kerja } \\
(\mathrm{X})\end{array}$ & 13 Item & 0,610 & Reliabel \\
\hline $\begin{array}{c}\text { Kinerja } \\
\text { Karyawan }(\mathrm{Y})\end{array}$ & 11 Item & 0,782 & Reliabel \\
\hline
\end{tabular}

Sumber : Data Primer, 2020

Tabel di atas menunjukkan, bahwa nilai Cronbanch Alpha> 0,60 yang menurut kriteria sebelumnya bisa dikatakan reliabel, sehingga dapat disimpulkan sesuai item pernyataan dari variabel $X$ dan $Y$ dapat diuji lebih lanjut.

\subsection{Uji Parsial (Uji t)}

Berdasarkan hasil perhitungan statistik, maka dapat diketahui bahwa variabel tentang Tekanan Kerja memiliki nilai $t$-hitung sebesar $1.870>$ nilai $t$-tabel sebesar 2,05 serta tingkat signifikannya lebih besar dari taraf kepercayaan

$$
{ }^{24} \text { Ibid, } 56 .
$$

sebesar 5\% yaitu $0,000>0,05$. Dengan demikian nilai menunjukan bahwa variabel Tekanan Kerja (X) tidak memberikan pengaruh secara signifikan terhadap variabel Kinerja Karyawan (Y). Berdasarkan uji $\mathrm{T}$ tersebut, hipotesis dalam penelitian ini yang menyatakan bahwa "Tekanan Kerja berpengaruh secara positif namun tidak signifikan terhadap Kinerja Karyawan di Bank Mega Syariah KC Palu".

\subsection{Uji Analisis Regresi Linier Berganda}

Berdasarkan tabel uji data regresi di atas, maka bentuk persamaan regresi dari model tersebut adalah sebagai berikut:

$\mathrm{Y}=25.669+0,371 \mathrm{X}$

Perhitungan di atas, dijelaskan dengan sebagai berikut:

1. Adapun nilai konstanta sebesar 25.669, artinya tanpa adanya Tekanan kerja maka Kinerja Karyawan Bank Mega Syariah KC palu memiliki persepsi positif.

2. Adapun koefisien Tekanan kerja sebesar 0,371, yang menunjukan bahwa apabila Tekanan kerja meningkat, maka dapat mempengaruhi Kinerja Karyawan Bank Mega Syariah semakin naik.

4.5 Pembahasan Hasil Penelitian
4.5.1 Pengaruh Tekanan Kerja $\left(X_{1}\right)$, Terhadap Tingkat Kinerja Karyawan Bank Mega Syariah KC Palu.

Berdasarkan hasil perhitungan statistik, maka dapat diketahui bahwa 
variabel tentang Tekanan Kerja memiliki nilai $t$-hitung sebesar 7,129> nilai $t$-tabel sebesar 1,988, serta tingkat signifikannya yaitu $0,74<0,05$. Dengan demikian nilai tersebut menunjukan bahwa variabel Tekanan Kerja (X) memberikan pengaruh namun tidak secara signifikan terhadap variabel Kierja karyawan (Y). Maka dari pembahasan ini menunjukan bahwa variabel Tekanan Kerja tidak berpengaruh secara signifikan terhadap Kinerja karyawan di Bank Mega Syariah KC Palu.

Hasil penelitian ini didukung oleh penelitian sebelumnya yang dilakukan oleh Karen shelia gustin yang membuktikan bahwa variabel Tekanan Kerja memiliki pengaruh positif dan signifikan terhadap Turnover Intention Karyawan di PT. Media Televisi Indonesia, dari hasil nilai $\mathrm{R}^{2}$ pada model penelitian adalah sebesar 0,557 atau $55,7 \%$.

Tekanan kerja atau job stress adalah perasaan tertekan yang dialami karyawan dalam menghadapi pekerjaan. Antara lain emosi tidak stabil, perasaan tidak tenang, suka menyendiri, sulit tidur, merokok yang berlebihan, tidak bisa rileks, cemas, tegang, gugup, dan tekanan darah yang meningkat. ${ }^{25}$

Dengan adanya Tekanan yang terjdi pada Karyawan Dengan adanya Tekanan yang terjdi pada Karyawan dapat mempengaruhi emosi, proses berpikir, dan kondisi seorang karyawan. Tekanan yang terlalu besar dapat mengancam kemampuan seseorang untuk menghadapi lingkungan. Sebagai hasilnya, pada diri para karyawan

\begin{tabular}{lcrr}
\hline 25 & A.A & Anwar & prabu \\
mangkunegara,"Manajemen & Sumber & Daya \\
Manusia Perusahaan"( (Bandung : PT & Remaja \\
Rosdakarya offset-) & $2011 ., 157$ & &
\end{tabular}

berkembang berbagai macam gejalah, dan dapat mengganggu pelaksanan kerja mereka. Kesimpulan bahwa tekanan kerja yang telalu besar dapat mempengaruhi kinerja karyawan di Bank Mega Syariah KC Palu.

\section{KESIMPULAN DAN SARAN}

Berdasarkan hasil pembahasan penelitian tersebut diatas, maka penulis dapat mengambil kesimpulan bawah variabel Tekanan Kerja memiliki nilai thitung sebesar 7,129> nilai $t$-tabel sebesar 1,988 , serta tingkat signifikannya yaitu $0,74<0,05$. Secara Parsial variabel Tekanan Kerja $(X)$ mempunyai pengaruh namun tidak secara Signifikan terhadap Kinerja Karyawan (Y) pada Bank Mega Syariah KC Palu, dengan besaran Tekanan kerja 13,2\%.

\section{PENELITIAN KEDEPAN}

Berdasarkan pada analisis dan kesimpulan yang berkaitan dengan penelitian ini, adapun penelitian kedepan yang dianjurkan adalah :

1. Disarankan agar pimpinan Bank Mega Sariah KC Palu, hendaknya memberikan perhatian kepada karyawan karena karyawan rentang mengalami tekanan dalam bekerja,

2. Memberikan kesempatan pada karyawan untuk menyampaikan ide, saran dan kritiknya, dengan demikian perusahan dapat mengatahui hal apa saja yang manajemen perlu lakukan untuk memperbaiki dan membantu karyawan nyaman dalam bekerja

3. Saran bagi peneliti selanjutnya dapat terus mengembangkan penelitian ini. Selain itu juga peneliti selanjutnya diharapkan dapat menambah variable penelitian yang lainnya. 


\section{DAFTAR PUSTAKA}

Astianto Anggit, Dkk." dalam skripsi Fina Nailatul Izzah "Pengaruh pengawasan dan beban kerja terhadap kinerja karyawan di konveksi "Lida Jaya" padurenan gebok kudus, http:/ / eprints.stainkudus.ac.id/i d/eprint/ diakses 20 januari 2019

Jalil, A. (2019). Pengaruh Beban Kerja, Stres Kerja dan Lingkungan Kerja Terhadap Kinerja Guru Madrasah Aliyah Negeri 2 Kota Palu. Jurnal Ilmu Perbankan dan Keuangan Syariah, 1(2), 117-134.

Jalil, A. (2020). Pengaruh Stres Kerja terhadap Kinerja Pegawai pada Madrasah Aliyah Negeri 2 Model Palu. Scolae: Journal of Pedagogy, 3(1), 40-48.

Kementerian Agama, Al-qur,an dan terjemahan, Q.S al-insyirah:5-8, bandung:cordoba,2018.

Mutis Thoby, Dkk. "Manajemen sumber daya manusia untuk perusahaan", RajaGrafindo persada, jakarta, 2009.,

Mangkunegara 2000.67 dalam skripsi dani praditya setiawan "Pengaruh beban kerja dan lingkungan kerja terhadap kinerja karyawan PT Macana Jaya cemerlang jawa tengah Universitas negeri jogyakarta 2016

Motgomer et al.,1996 dalam skripsi Rizki aulia kusuma wisanto"Analisis dampak locus of control pada tekanan kerja, kepuasan kerja dan kinerja auditor"universitas diponegoro 20012.,15 http:/ / eprints.undip.ac.id diakses 19 april 2019
Mangkunegara, prabu A.A Anwar," Manajemen Sumber Daya Manusia Perusahaan"PT Remaja Rosdakarya offset-bandung 2011.

Nurdin, N., Stockdale, R., \& Scheepers, H. (2012). The Influence of External Institutional Pressures on Local E-Government Adoption and Implementation: A Coercive Perspective within an Indonesian Local E-Government Context. In H. Scholl, M. Janssen, M. Wimmer, C. Moe \& L. Flak (Eds.), E-Government and E-Participation (Vol. 7443, pp. 13-26): Springer Berlin / Heidelberg.

Nurdin, N., Stockdale, R., \& Scheepers, H. (2014). Coordination and Cooperation in E-Government: An Indonesian Local EGovernment Case The Electronic Journal of Information Systems in developing Countries, 61(3), 1-21.

Nurdin, N. (2018). Institutional Arrangements in E-Government Implementation and Use: A Case Study From Indonesian Local Government. International Journal of Electronic Government Research (IJEGR), 14(2), 44-63. doi: 10.4018/ijegr.2018040104

Nurdin, N., Azizah, W. N., \& Rusli, R. (2020). Pengaruh Pengetahuan,Kemudahan dan Risiko Terhadap Minat Bertransaksi Menggunakan Finansial Technology (Fintech) Pada Mahasiswa Institut Agama Islam Negeri (IAIN) Palu Jurnal Ilmu Perbankan dan Keuangan Syariah, 2(2), 199-222.

Nurdin, N., Musyawarah, I., Nurfitriani, N., \& Jalil, A. (2020). Pengaruh Pelayanan Mobile Banking 
Terhadap Kepuasan Nasabah (Studi Pada Mahasiswa Perbankan Syariah IAIN Palu) Jurnal Ilmu Perbankan dan Keuangan Syariah, 2(2), 87-104.

Prabu A.A Anwar, Perusahaan" (Bandung: PT Remaja Rosdakarya offset-), 2011

Rokhman Wahibur, Manajemen Sumber Daya Manusia, Nora Media Enterprise, Kudus, 2011.

Sugiyono, Metode Penelitian Bisnis, ALFABETA, Bandung, 2008.

-------, Metode Penelitian Pendidikan Pndekatan Kuantitatif, Kualitatif, dan R dan D.Cet. 20, Bandung: Alfabeta, 2014.

Siregar Sofian, Statistik Parametrik untuk Penelitian Kuantitatif, Edisi 1, Cet. 3, Jakarta: PT. Bumi Aksara, 2015.

Wibowo,"manajemen kinerja"PT Rajagrafindo persada, jakarta.2007. Wibowo, Manajemen Perubahan, Pt RajaGrafindo Persada, Jakarta, 2006. 